\title{
Geophysical Investigation of the Triassic Salt Material Hazard: El Fahs Case Example (Northern Tunisia)
}

\author{
Mohamed Khaled Bouzid1,2, Adel Klai1,2, Romdhane Haddad1,2, Mohamed Chedly Rabia ${ }^{1,2}$ \\ ${ }^{1}$ Faculty of Sciences of Bizerte, University of Carthage, Tunis, Tunisia \\ ${ }^{2}$ Research Laboratory “Geomatics of Geosystems” LR19ES07, Faculty of Letters, Arts and Humanities of Mannouba, Mannouba \\ University, Manouba, Tunisia \\ Email: bouzidmohamedkhaled@yahoo.fr
}

How to cite this paper: Bouzid, M.K., Klai, A., Haddad, R. and Rabia, M.C. (2020) Geophysical Investigation of the Triassic Salt Material Hazard: El Fahs Case Example (Northern Tunisia). International Journal of Geosciences, 11, 729-744.

https://doi.org/10.4236/ijg.2020.1111036

Received: July 30,2020

Accepted: November 6, 2020

Published: November 9, 2020

Copyright $\odot 2020$ by author(s) and Scientific Research Publishing Inc. This work is licensed under the Creative Commons Attribution International License (CC BY 4.0).

http://creativecommons.org/licenses/by/4.0/

(c) (i) Open Access

\begin{abstract}
The Tunisian territory (area of diapirs) is exposed to the risks of ground movements linked to water, some of which are related to the phenomenon of dissolution of gypsum, allowing the appearance of underground cavities which present natural risks and set people in danger. The analysis of the hazard was determined by the field study coupled with the application of geophysical methods to locate and map the cavities and identify their dimensions and their positions in the subsoil. In the region of $\mathrm{El} \mathrm{Fahs}(40 \mathrm{~km} \mathrm{NW}$ of Tunis): we used a non-destructive method, georadar (GPR) with a $200 \mathrm{MHz}$ antenna bandwidth, and an electric method, by using the electric tomography of which we have applicated the sequence of dipole-dipole measurement. The results obtained were examined and interpreted according to $2 \mathrm{D}$ profiles. The geophysical methods of GPR and electrical tomography aim to detect many calvities in different depths. However, the geological radar was able to identify several cavities and the zones of dissolution whose investigation depth did not exceed the first 3 meters. On the contrary, the electric tomography method allowing the presence of several deeper underground cavities with larger dimensions extended to 64 meters. To conclude, the geological and hydrogeological contexts of the terrain studied and on the state of the soil and subsoil allow us to better understanding the mechanisms of the establishment of the dissolution phenomenon and the appearance of cavities in the basement. The analysis of the predisposing factors present in the study area shows that the geodynamic context of the Triassic ascent takes place according to a precise thermodynamic process that favors the phenomenon of dissolution of the gypsum.
\end{abstract}

\section{Keywords}

Triassic Materials, Natural Hazards, Underground Cavities, Thermodynamic 
Process, GPR, Electric Tomography

\section{Introduction}

Around the world, natural disasters linked to the presence of holes and the collapse of the ground are different and multiple, causing significant socio-economic damage. Several are the predisposing and triggering factors of this phenomenon linked mainly to the presence of cavities in the basement. Indeed, the lithological nature of the carbonated or evaporitic soil with solubility and significant dissolution produces deep voids inducing the subsidence and sudden collapse of a portion of land. Tunisia, like all the countries of the world, was not immune to these natural risks, which cause economic losses every year.

The north of Tunisia is characterized by these Triassic outcrops aligned in a NE-SW direction [1] [2] [3] [4] [5]. The Triassic in this area is characterized by generally evaporitic facies which will be exposed, in the presence of acidic water, to the phenomenon of dissolution of gypsum materials and the presence of numerous cavities and underground caves [6]. The latter is susceptible to the collapse of the ground, which presents natural risks for the population and which can cause damage to infrastructure or buildings.

In recent decades, several structural studies have been carried out on the mode of setting up Triassic structures in Tunisia [7]-[12], on the other hand, work on the danger that can provide these evaporitic outcrops is almost absent. In this context, in the north of Tunisia, several urban development projects such as the installation of new road or motorway networks have not taken into account the specificity of the Triassic terrain, which still poses problems for developers. The risk of soil collapse linked to the dissolution of gypsum is an unstable or dangerous situation requiring a decision and which must be resolved in these types of projects. Thus, this natural phenomenon imposes more economical investment on developers, and even sometimes causes socio-economic damage. The region of el Fahs (NW of Tunis) is limited by the zone of diapirs [10] [13].

In this case, it is necessary to locate and map the hazard zones to draw the attention of developers to the potential or real dangers presented by certain portions of the Triassic territory in relation to nature and the characteristics of the land. There are many geophysical prospecting methods used for the detection of underground anomalies [14] [15] [16] [17] whose most adaptable methodology for the detection and mapping of these cavities is mainly based on the use of GPR geological radar techniques and electric tomography [18]. In this study, in the case of geological radar, we used an antenna with $200 \mathrm{MHz}$ bandwidth influenced by the electrical conductivity of the surrounding, which causes the attenuation of the signal and limits the depth of investigation [19]. And for electric tomography, we applied the dipole-dipole measurement sequence to guarantee a better depth of study and have a good resolution for large anomalies. These 
techniques have given good results in recognition of the locality and the depth of certain underground cavities.

\section{Geography}

The region of el Fahs is part of the Tunisian Eastern Atlas is located in the NW of Tunisia (Figure 1), covering an area of about 80 square $\mathrm{km}$. In the NW, the study area is delimited by the diapir area [10] [13], the Zaghouane accident [20] [21] to the south and the Sedjenene plain to the east [22]. The study area is located about $2 \mathrm{~km}$ from the city of El Fahs (Zaghouane Governorate). It is represented by gypsum outcrops delimited by the beds wadi Miliane, which is a River flowing northeast of the Tunisia over a distance of 160 kilometers, making it the second most extended perennial stream in the country after the Mejerda.

\section{Geology}

In this area, the stratigraphic series extends from the Triassic to the Quaternary (Figure 2). The Triassic is generally chaotic in appearance composed of gray marls, gypsum and dolomite [12]. Clays represent the Lower Cretaceous series, marls, sandstones and limestones. In contrast, the Upper Cretaceous series are represented by dark marls, marl-limestones and centimetric beds with metric limestone [22]. The region of el Fahs was the seat like all the northern Tunisian part of the structural events which extend from the Jurassic to the Quaternary known by extensive tectonics of the Mesozoic and the compressive events of the Cenozoic [23].

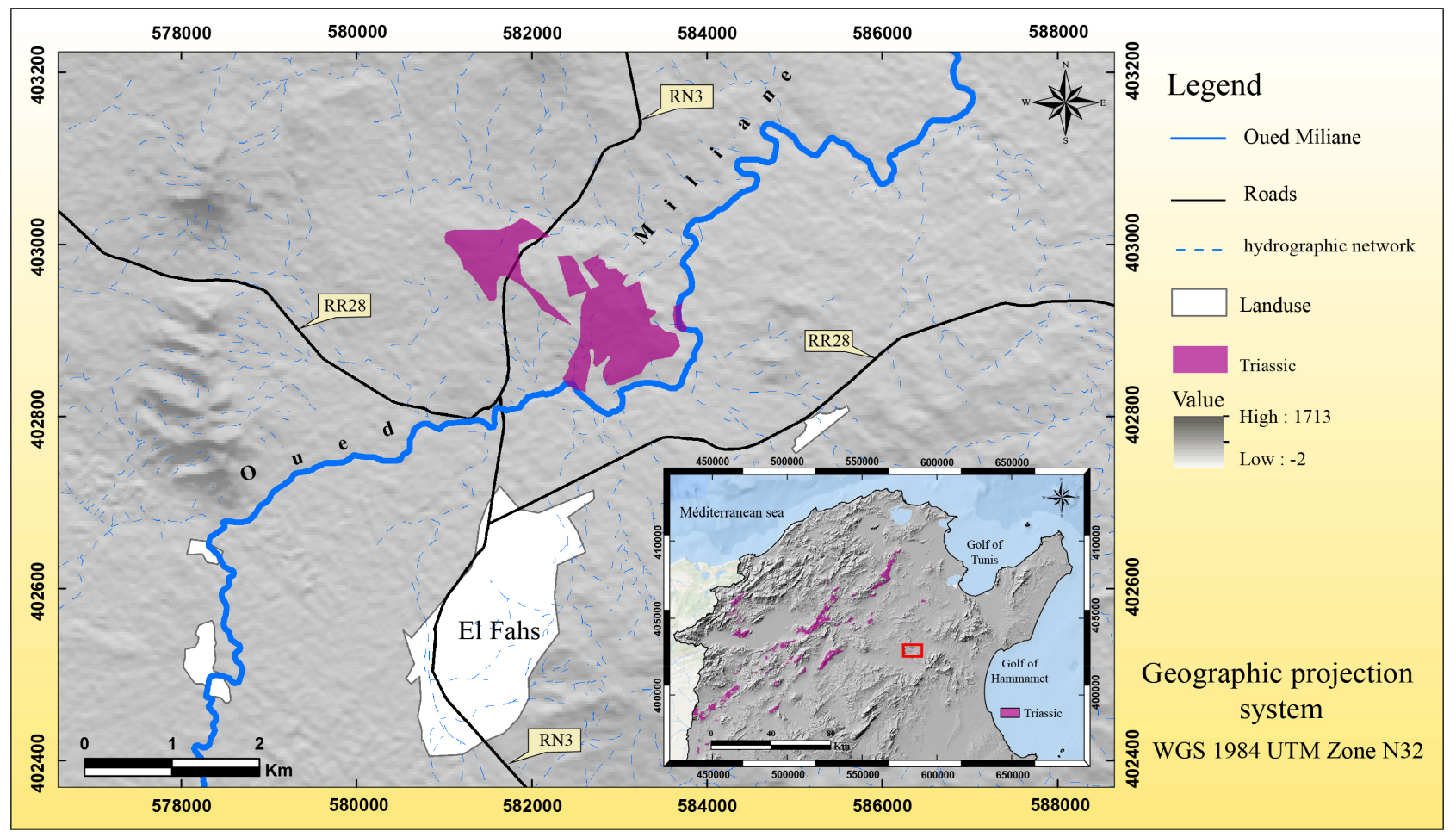

Figure 1. Location map of the El Fahs region. 


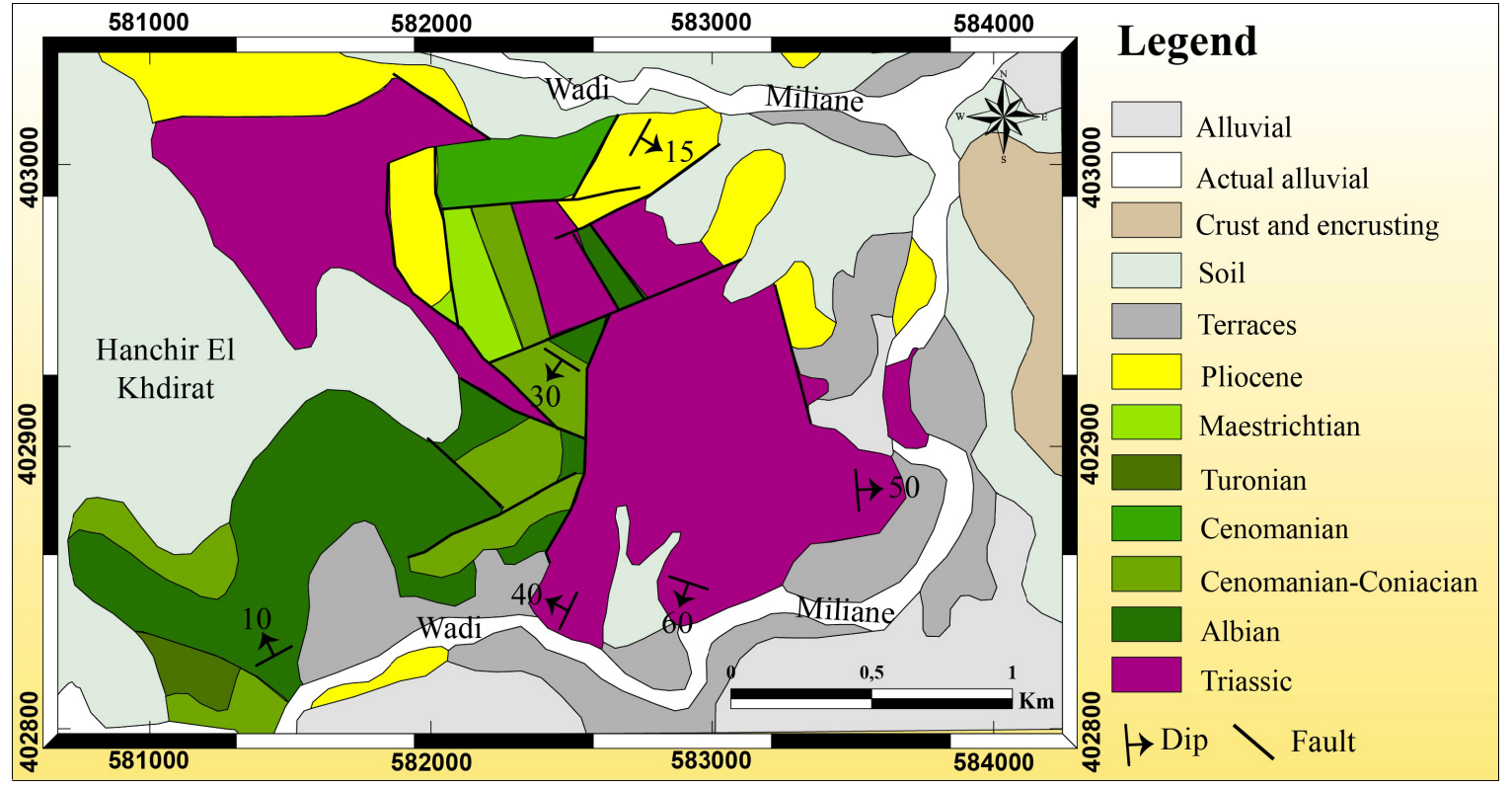

Figure 2. Geological map of the El Fahs region.

\section{Field Observation}

The study area with a Mediterranean climate is of Mediterranean type, characterized by mild and wet winters and hot, dry summers. The average temperature is $17^{\circ} \mathrm{C}$, with a significant evapotranspiration potential ranging from $1400 \mathrm{~mm}$ to $1500 \mathrm{~mm}$ [24]. The average precipitation varies according to the periods between $400 \mathrm{~mm} /$ year and $600 \mathrm{~mm} /$ year. A field study was carried out to highlight all the factors likely to trigger the dissolution process of evaporites and the presence of cavities in the subsoil. The Triassic mass studied is composed of a gypsum-sandstone-marly complex of which we find the saccharoid gypsum (Figure 3(a) and Figure 3(b)). It is a soft rock, scratchable with the nail and a low density of 2.3 .

According to the geological map (Figure 2), the El Fahs region is affected by a network of faults and fractures in the NW-SE and NE-SW direction at the Triassic contact and the Cretaceous layers. All of the fractures observed have a very important role in the infiltration of rainwater and their circulation in-depth, which cause the dissolution of gypsum (Figure 3(c) and Figure 3(d)). This is the case in our sector of study where we have observed the existence of various fracturing affecting the gypsum outcrops and the appearance of several mineralization figures of the stockworks type, which are set up due to the temperature gradient and high pressures (Figure 3(e) and Figure 3(f)).

The presence of water is the main factor triggering the phenomenon of gypsum dissolution. The rains have fallen in the ground, quickly fed the surface aquifers in favor of the cracked structures which overcome. The surface runoff and the fluctuation of the water level as a function of the amount of rainfall allow the increase of water content in the soluble materials of the soil and in-depth. Consequently, the change in the mineralogical composition of the 

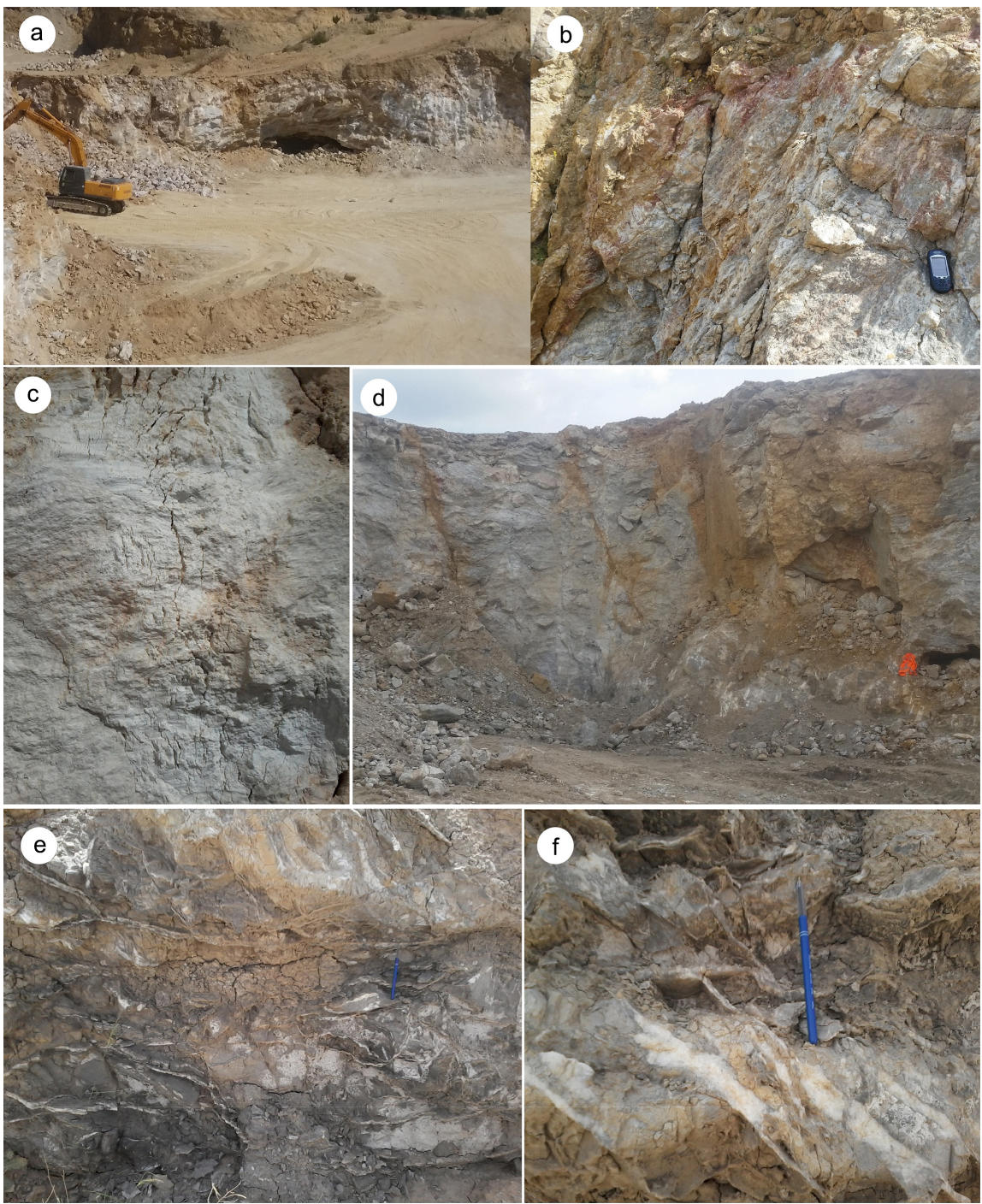

Figure 3. (a): Field photo showing the quarry of saccharoid gypsum in the El Fahs region. (b): Chaotic gypsum aspect of Triassic outcrops, (c): Fractures networks affected the saccharoid gypsum. (d): Field photo showing the presence of fracture affecting gypsum outcrops. (e) and (f): Field photo illustrating stockworks type mineralization.

evaporitic rocks whose processes of chemical alteration and dissolution of the soil remain very extensive and well developed. The Miliane wadi beds present a factor of the dissolution of gypsum. This river delimits the gypsum outcrops and plays a significant role in the dissolution of evaporites. The dissolution process is active if there is a high-speed water circulation in contact with gypsum formations. Several zones where the Gypsum Triassic is intersected by the flows of the Miliane wadi present figures of dissolution of the gypsum caused by the circulation of water at high speed.

The Triassic of the study region shows the existence of various forms of dissolution and the presence of cavities of different sizes and of varying depth (Figure 4). When they are close to the surface, they present areas at risk of collapsing the ground, revealing voids threatening property and people. It will be 


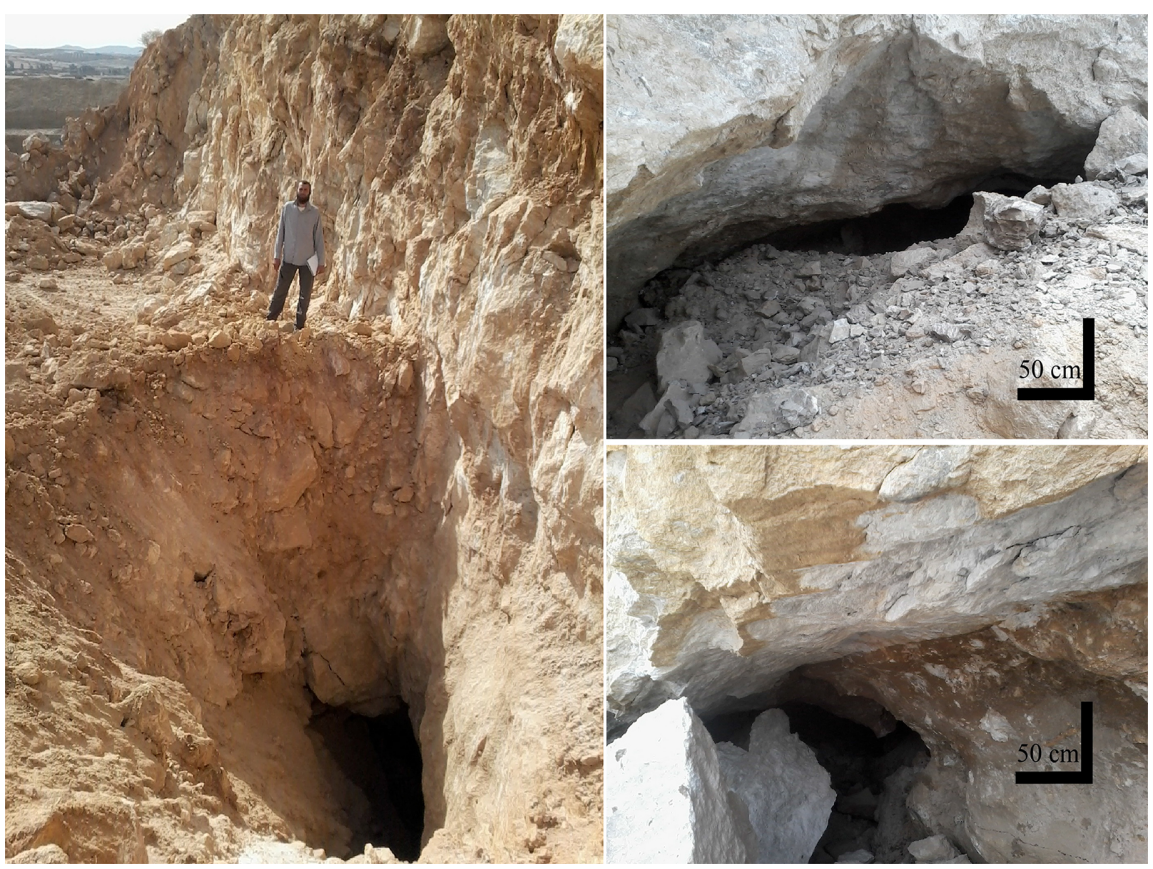

Figure 4. Field photos showing the presence of various underground cavities of different dimensions in the gypsum masses.

essential to intervene by using geophysical methods for the detection and mapping of underground cavities in order to minimize the damage linked to the presence of these anomalies.

\section{Geophysical Prospecting}

The field and geophysical studies carried out in the El Fahs region for the detection of underground cavities linked to the phenomenon of gypsum dissolution were oriented around a coupling of two integrated approaches, grouping field observations and the use geophysical methods of georadar and electric tomography. It is also based on the analysis of predisposing factors favorable to the presence of gypsum dissolution processes from the study of the sedimentological and mineralogical characteristics of the evaporitic formations favorable to dissolution. Geophysical surveys have been carried out on the Triassic gypsum outcrops whose substrate has various cavities.

In this part, we used several techniques to visualize anomalies and underground cavities of GPR coupled with electric tomography. Using observations and collecting field data, we were able to identify and locate the areas to be surveyed. In this site, we carried out-coupling of 3 to 4 georadar profiles and electric tomography to detect the cavities in the basement (Figure 5(a)). The geophysical surveys were carried out between June 2019 and February 2020, by a team of doctoral students from the Faculty of Sciences of Bizerte and the "Geomatics of Geosystems" research laboratory of the Faculty of Arts and Humanities of Mannouba (Figure 5(b)). 


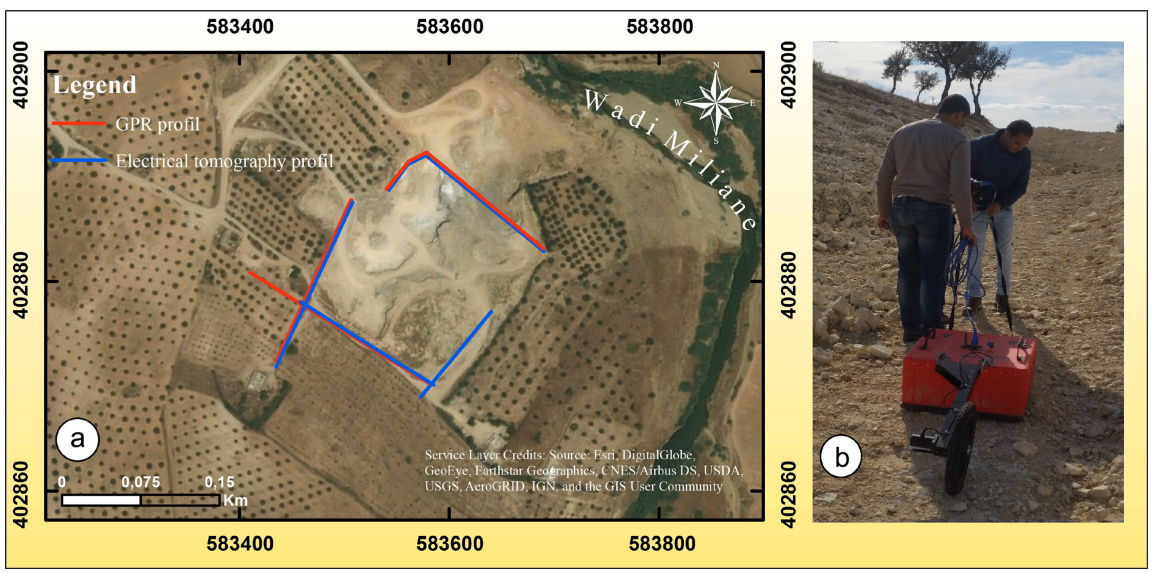

Figure 5. (a) Location of georadar profiles and electric tomography; (b) Field photo of a GPR geophysical survey by $200 \mathrm{MHz}$ antenna.

The materials used to acquire the subsurface GPR are a $200 \mathrm{MHz}$ antenna with a GSSI SIR-4000 control unit from the company MDS. Into the ground, a transmitting antenna sends very short pulses with frequencies ranging from 10 $\mathrm{MHz}$ to $2 \mathrm{GHz}$. These pulses cause a wavefront that propagates through the investigated environment. In contact between two substrates with different dielectric properties (The contact between two layers, cavity, buried object, fracture...), a part of the energy of the waves will be reflected, while the remainder of the energy will be penetrated deeper [19]. The reflected waves are picked up at the surface by the receiving antenna. The profiles obtained were processed by Randan 7 software. Georadar prospecting was carried out on 3 sites in the southern part of the Triassic outcrop within a gypsum quarry. The prospected site is characterized by the presence of shallow and reduced-size cavities that have already been observed and which do not exceed 2 meters in depth. The obtained measurements called "radargram" were treated (Filtering, Tzéro, deconvolution and migration) to improve their contrasts, eliminate the noises and determine the average dielectric constant to use to have exact depths for the sought targets.

The second geophysical method used is an electric tomography. The measurement of the resistivity of a structure is achieved 1) by injecting an electric current into the ground using injection electrodes, A and B, and 2) by determining the difference of potential by computing the potential difference using measuring electrodes, $\mathrm{M}$ and $\mathrm{N}$. The number of electrodes, as well as their arrangement, allow to define the electrical device to be used. In our case, the dipole-dipole configuration was adopted, making it possible to acquire a large number of measurements and guarantee a better depth of investigation. The measurement device consists in particular of a Syscal R1Plus-type resistivity meter from IRIS Instruments and a connection system that can receive up to 72 electrodes spaced $5 \mathrm{~m}$ apart. The acquired data are presented in the form of resistivity panels using the data inversion method of Loke and Barker [25]. 


\subsection{Prospecting by Geological Georadar Method}

The GPR profiles produced in the study area (see Figure 5(a)) show a lateral variation of responses linked to the nature of the materials explored. The high resolution of the $200 \mathrm{MHz}$ antenna makes it possible to free an investigation depth of $3 \mathrm{~m}$ (Figure 6). The georadar data obtained in the profiles translate the characteristic responses of the change in the dielectric permittivity of the prospected medium.

The roof of the cavity presented in the form of a black reflection (Figure $6 \mathrm{~T} 1$ ) reflects the passage from a medium with high permittivity ( 8 in our case considering the presence of evaporites) to a medium with low permittivity (1 linked to the presence of air). Theoretically, the response of an empty cavity is suitable for the existence of an energy resonance, which is manifested by the appearance of multiple reflections that propagate in the air as a function of time and depth. The T1 profile shows a lateral heterogeneity of the diffractions and reflections characterized by the surface development with negative amplitude typical of the zones of low dielectric permittivity (voids), which corresponds in a frankly evaporitic facies (permeable).

The $200 \mathrm{MHz}$ profile (Figure 7) produced at the western part of the quarry, shows the development of a dense network of fractures well exploited by rainwater in order to produce subsidence areas (Figure $7 \mathrm{~T} 3$ and T4) or for cavities 1 $\mathrm{m}$ deep at the level of the evaporitic facies. These cavities are characterized by their typical response on the radargrams translated by hyperbolas of black summit color. This response is caused by the permittivity contrast between the limestones (8) and the vacuum (1). The (NE-SW) part of the profile shows a signal attenuation surface developed from the $45 \mathrm{~m}$ marks, characteristic of areas with high electrical permittivity (clays...).

\subsection{Prospecting by Electric Tomography Method}

For the detection of underground cavities, it was adopted to use the dipole-dipole measurement device for its high sensitivity to surface heterogeneities and its good lateral resolution. The electrical imaging campaign carried out in the Triassic outcrops was conditioned according to the possibility of implementation and installation of the measurement device and the confirmation and verification of certain cavities known or detected by the geological radar and other deeper. 2 profiles were made $\mathrm{P} 1$ and $\mathrm{P} 2$ with the use of 72 electrodes spaced $5 \mathrm{~m}$ apart to guarantee better lateral and vertical resolution. The pseudo-sections obtained of apparent resistivity measured allow, before any inversion, to answer the question posed of the presence or not of cavities.

The pseudo-section calculated for the dipole-dipole measurement configuration within the gypsum formation illustrates a lateral and in-depth variation of the electrical resistivities, which varies between 13.5 and $3032 \mathrm{Ohm} \cdot \mathrm{m}$. Profile P1 (Figure 8) shows three distinct zones with high electrical resistivities $(>3032$ $\mathrm{Ohm} \cdot \mathrm{m}$ ) located NW and SE of the profile and a third anomaly is centered, 
NE

SW

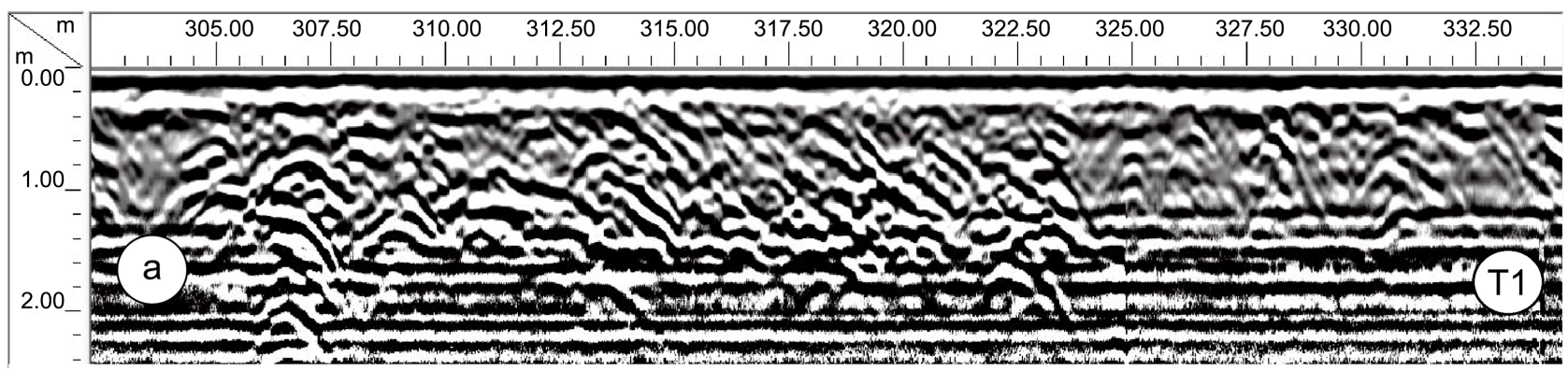

NE

SW

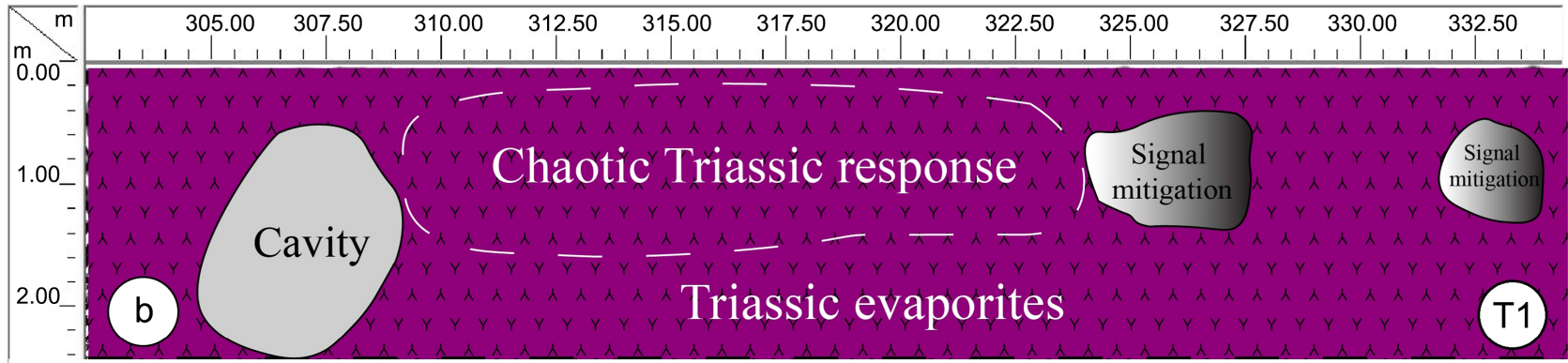

NW

SE

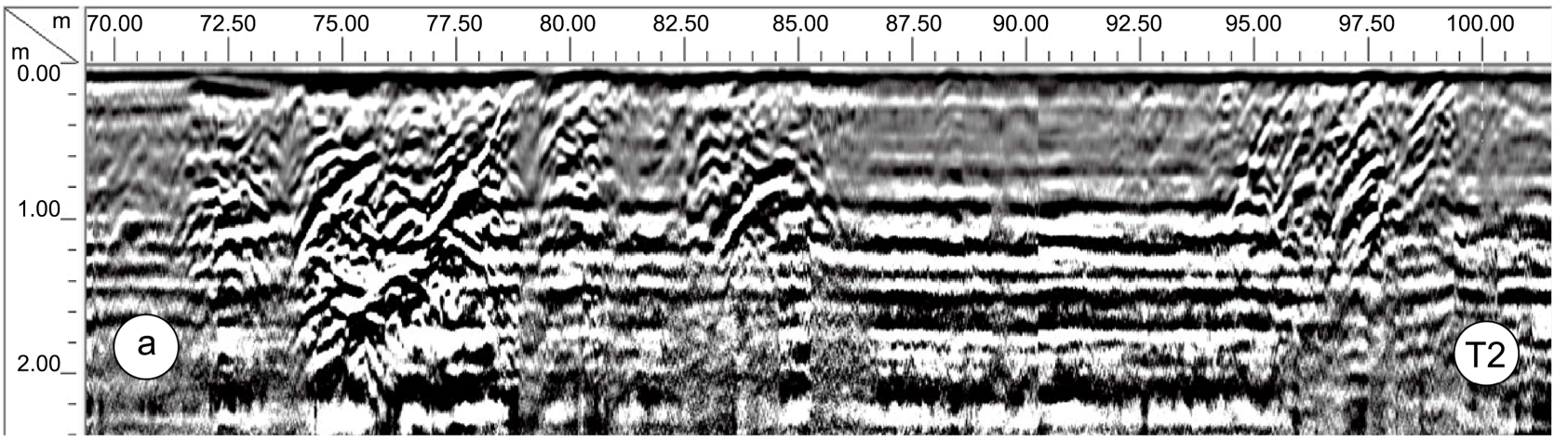

NW

SE

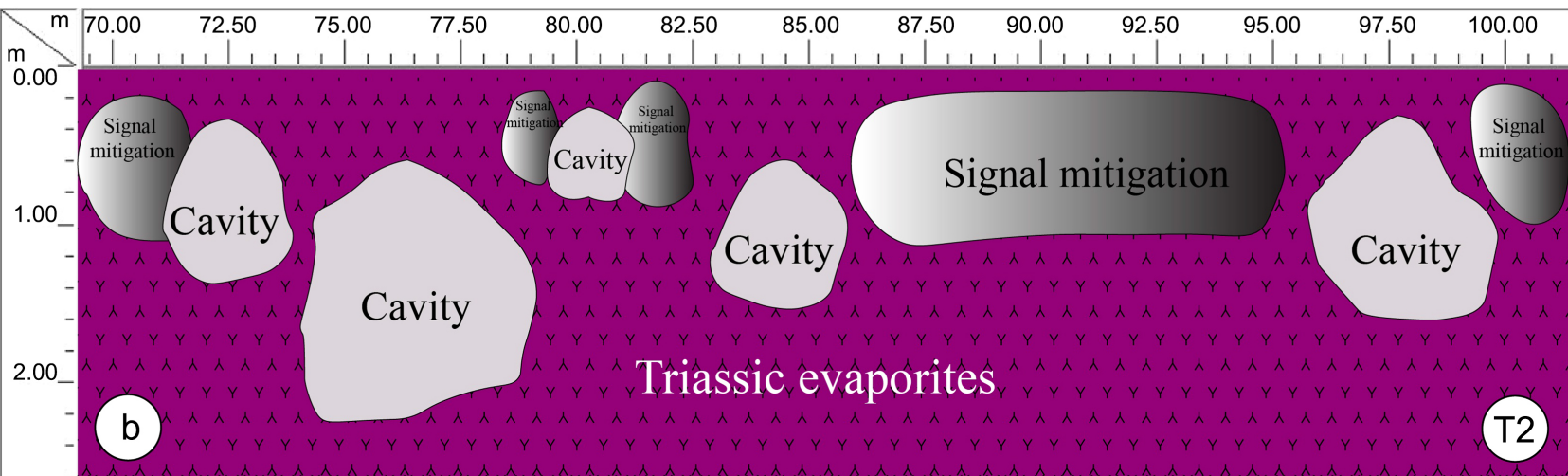

Figure 6. GPR profiles T1 and T2 acquire by $200 \mathrm{MHz}$ antenna. (T1, (a)): GPR $200 \mathrm{MHz}$ profile processed acquired all along the NE-SW direction (T1) section. (T1, (b)): Interpretative diagram illustrating the chaotic response of gypsum evaporites and the presence of a cavity at a depth of $50 \mathrm{~cm}$. (T2, (a)): Processed GPR profile acquired all along the section (T2) of NW-SE direction. (T2, (b)): Interpretative diagram, which shows the existence of 5 near-surface cavities of various dimensions and signal attenuation zones. 
NE

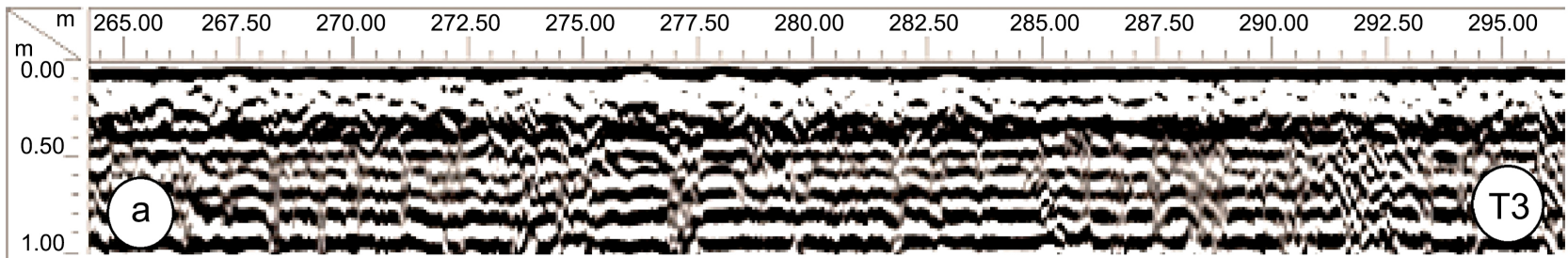

NE

SW
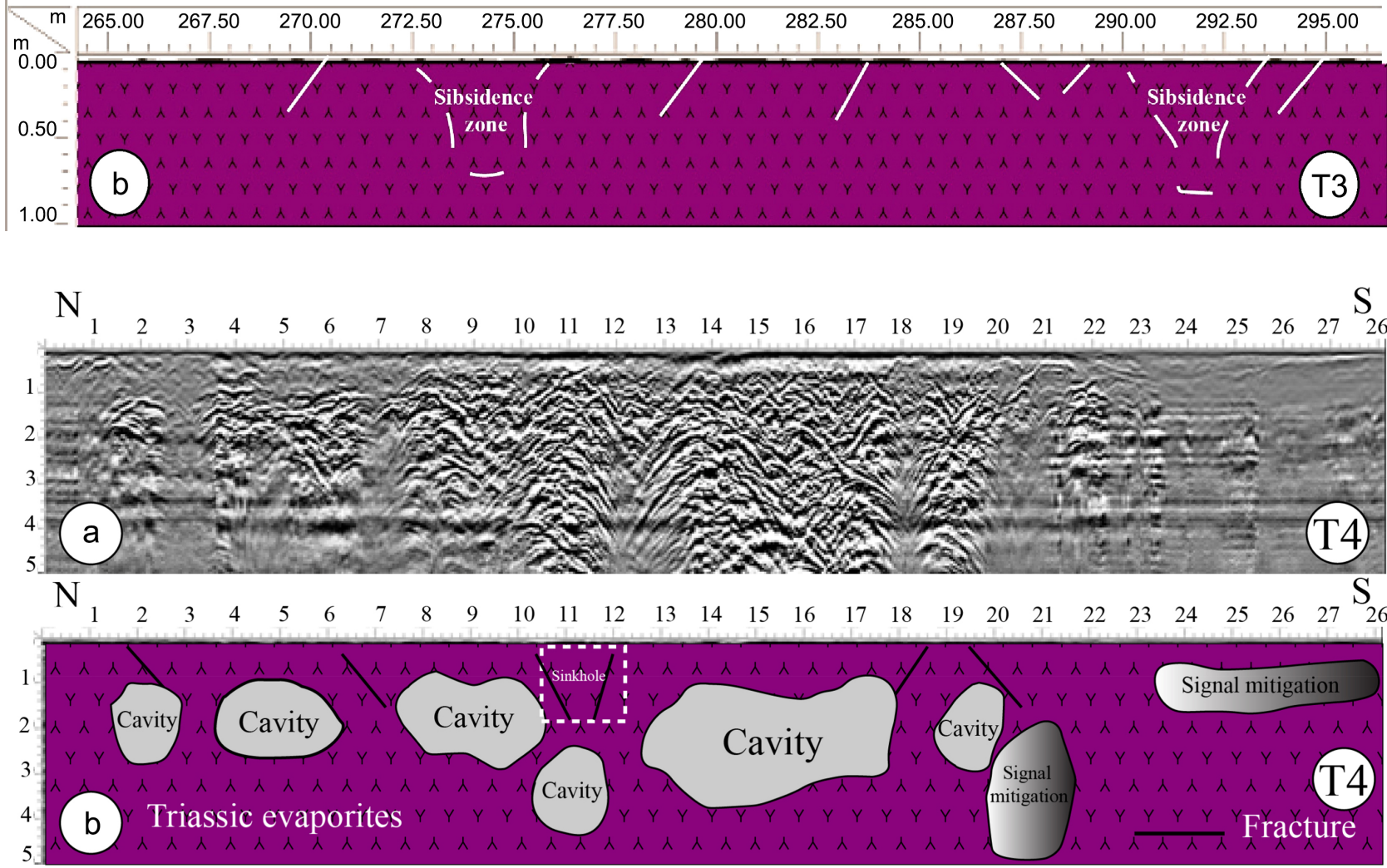

Figure 7. GPR profiles T3 and T4 aquired by $200 \mathrm{MHz}$ antenna. (T3, (a)): GPR $200 \mathrm{MHz}$ treated profile acquired all along the NE-SW section (T3). (T3, (b)): An interpretative diagram showing the presence of several fractures and areas of subsidence. (T4, (a)): GPR $200 \mathrm{MHz}$ treated profile acquired all along the section (T4) of NW-SE direction. (T4, (b)): All of the cavities present in the subsurface followed by a network of fractures and signal attenuation zones reflecting the presence of water.

\section{NE}

Depth Iteration 3 RMS error $=4.6 \%$

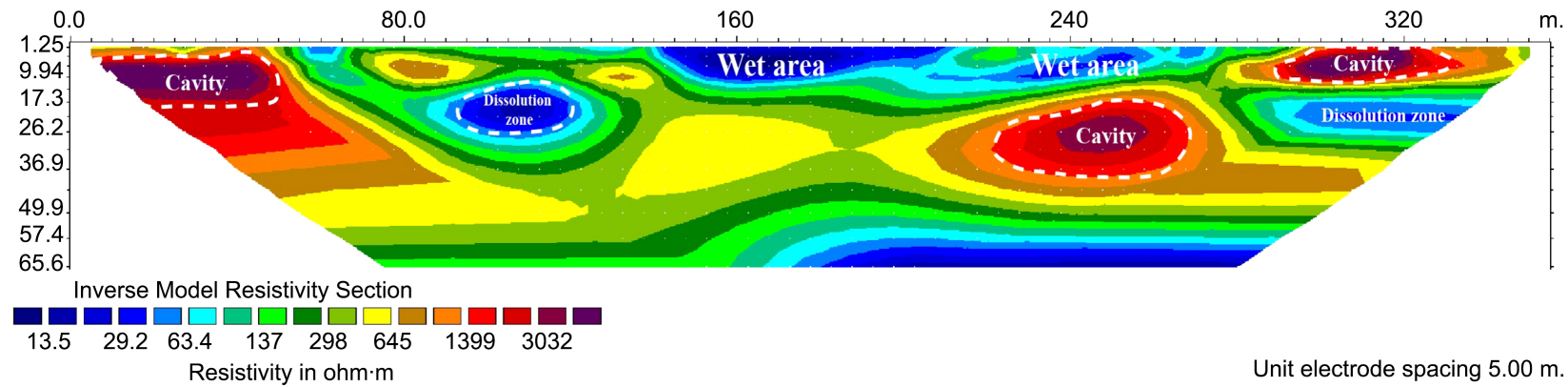

Figure 8. Pseudo-section, which shows the existence of 4 cavities and dissolution zone. 
which will be interpreted as underground cavities. For the first anomaly located $\mathrm{NE}$ and about $5 \mathrm{~m}$ deep, it has a significant dimension of around $50 \mathrm{~m}$ in width and $10 \mathrm{~m}$ in amplitude. The second cavity illustrated to the SE in profile, which has already been observed in the field, shows the existence of a vacuum within the gypsum layers is localized in the subsurface with a more or less significant extent of $35 \mathrm{~m}$ in width and around $8 \mathrm{~m}$ in amplitude. In the center of the profile, there is the appearance of another anomaly with a high electrical resistivity (between 1399 and $3032 \mathrm{Ohm} \cdot \mathrm{m}$ ), it is a very deep cavity of about $25 \mathrm{~m}$ digging in the formations clay-gypsum.

A zone of low resistivity $(<63.4 \mathrm{Ohm} \cdot \mathrm{m})$ and with high electrical conductivity represented in the form of a pocket has been detected in-depth around $15 \mathrm{~m}$; it is probably a dissolution zone soaked in water. It is a very deep cavity of about 25 $\mathrm{m}$ digging in clay-gypsum formations. A zone of low resistivity $(<63.4 \mathrm{Ohm} \cdot \mathrm{m})$ and with high electrical conductivity represented in the form of a pocket has been detected in-depth around $15 \mathrm{~m}$. It is probably a dissolution zone soaked in water. It is a very deep cavity of about $25 \mathrm{~m}$ digging in clay-gypsum formations. An area of low resistivity $(<63.4 \mathrm{Ohm} \cdot \mathrm{m})$ and with high electrical conductivity represented in the form of a pocket has been detected in-depth around $15 \mathrm{~m}$; it is probably a dissolution zone soaked in water.

The prospected area has an abundance of gypsum, shows variable resistivities. The resistivities are highlighted all along profile P2 (Figure 9), have larger shapes and dimensions of the cavities than at the level of profile P1. High resistivity $(>1328 \mathrm{Ohm} \cdot \mathrm{m})$ translates the existence of large cavities that exceed $50 \mathrm{~m}$ in width and significant height exceeding $15 \mathrm{~m}$. The presence of these large cavities can cause the ground to collapse and endanger people and things.

Figure 10 determines the measurements made in the dipole-dipole device in the gypsum karst medium. The measurements illustrate a heterogeneous medium with depths exceeding $20 \mathrm{~m}$, composed of saccharoid gypsum with high resistivity $(>689 \mathrm{Ohm} \cdot \mathrm{m})$ and a mixture of clay and sandstone of low resistivity (between 188 and $333 \mathrm{Ohm} \cdot \mathrm{m}$ ). The pseudo-section P3 highlights a rounded cavity located $1 \mathrm{~m}$ deep, its size more or less important. A large resistant pocket $(>3,044 \mathrm{Ohm} \cdot \mathrm{m})$ has been detected about $18 \mathrm{~m}$ deep and relatively bulky, which shows the vertical spread of vacuum and reaches the subsurface where it can cause localized collapse (or sinkhole). Other conductive pockets have been positioned on the $\mathrm{P} 3$ profile, approximately 6 to $16 \mathrm{~m}$ deep.

\section{Results and Discussion}

Several factors controlled the presence of underground cavities in the Triassic gypsum outcrops of the El Fahs region. From a geological point of view, the Triassic salt of the El Fahs region was the source of many tectonic phases during which the gypsum formations are exposed. During separation and migration of Triassic during the compressive and distensive tectonic phases, changes in temperature and pressure as a function of depth cause the appearance of fractures of 
NNE

SSW

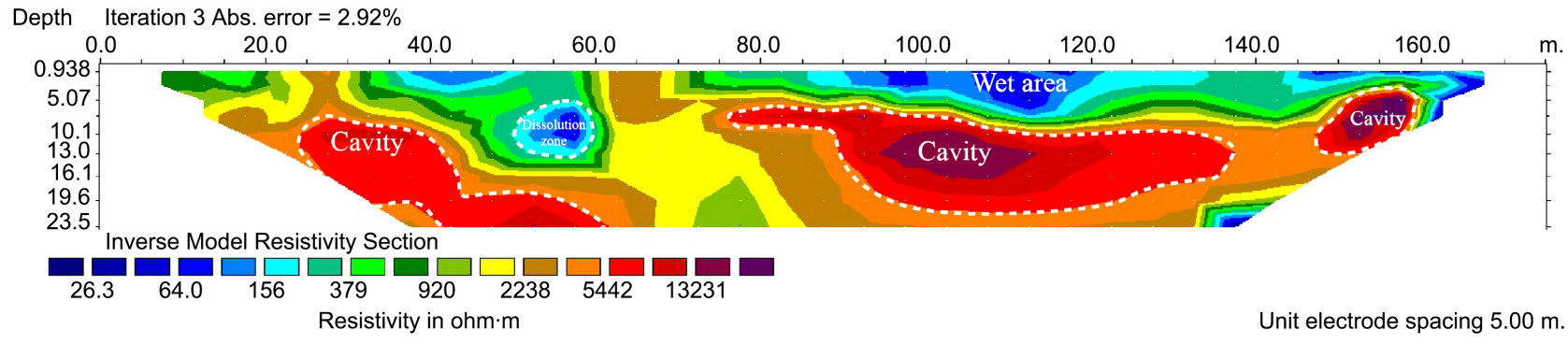

Figure 9. Pseudo-section P2 illustrating the existence of various large underground cavities.

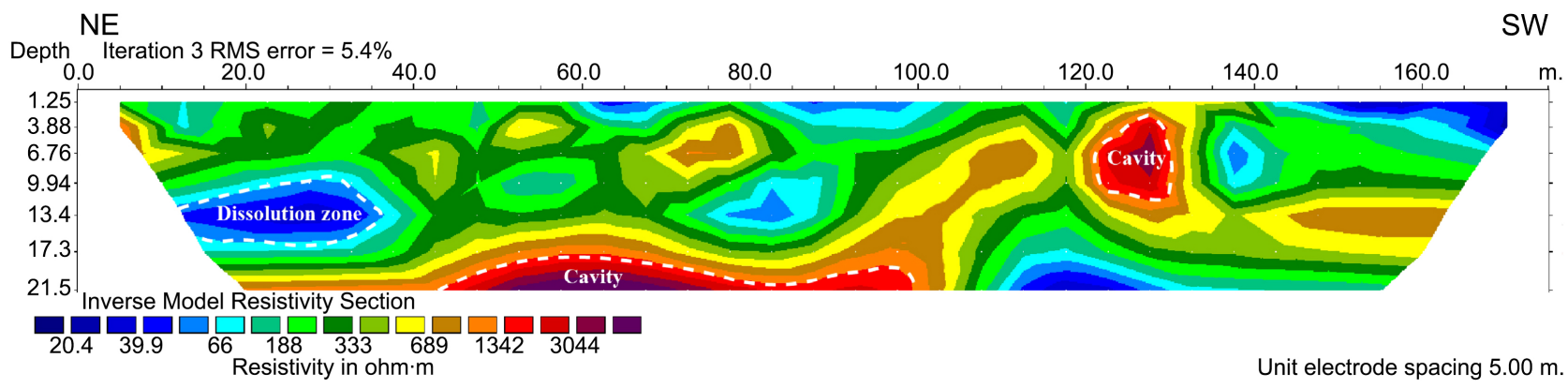

Figure 10. Pseudo-section P3 showing the existence of underground cavities in the subsurface and in-depth.

the roof of the intrusion and its surroundings. Therefore, the opening of these fractures allowing the injection of the silicate liquid into the fractures followed by rapid crystallization at low temperature, which induces the formation of crystal veins. Thus, these discontinuities favor the circulation of rainwater in-depth and the creation of voids following the process of dissolution of evaporites.

The gypsum present in the study area is hydrated calcium sulfate (Ca$\mathrm{SO}_{4} \cdot 2 \mathrm{H}_{2} \mathrm{O}$ ), formed by minerals resulting from critical evaporitic processes. The properties/characteristics of gypsum soils susceptible in the presence of water to the appearance of underground cavities, including gypsum characterized by a low density (2.1), thus by a very low plasticity threshold favoring under the effect of geothermal gradients to migrate vertically or laterally. In addition, the saccharoid nature of gypsum formed in the Triassic terrains shows a very strong solubility capable, under conditions of water circulation of rainwater and the drainage network of wadi Miliane, to dissolve quickly and the formation of karts likely according to their dimensions. and their depths to the collapse of the ground (Equation (1)).

$$
\mathrm{CaSO}_{4} \cdot 2 \mathrm{H}_{2} \mathrm{O} \Leftrightarrow \mathrm{Ca}^{2+}+\mathrm{SO}_{4}^{2-}+2 \mathrm{H}_{2} \mathrm{O}
$$

Under atmospheric pressure conditions, for example, the solubility varies between 0 and $20^{\circ} \mathrm{C}$, from 2.15 to $2.53 \mathrm{~g} / \mathrm{l}$ and has an optimum of $2.67 \mathrm{~g} / 1$ at $40^{\circ} \mathrm{C}$ [26], the dissolution processes continue until they reach chemical equilibrium. This dissolution leads to the loss in the subsoil of solid matter and the creation of voids, of more or less important dimensions. On the surface, changes in the structure of the ground at depth can cause slow subsidence of the soil or the 
formation of sudden collapses on the surface (Figure 11).

The presence of stockworks type's mineralization and hydrothermal veins which correspond to fractures filled with calcites following a high temperature and pressure gradient allowing the crystallization of hydrothermal fluids reflect that the study area was the seat of frequent hydrothermalism. The underground circulation of hot water, favored by a heat source, dissolves the minerals present in the rocks crossed and causes the creation of a vacuum and the injection of silicate liquids in the fractures followed by rapid crystallization at low temperature [27].

2D georadar measurements by $200 \mathrm{MHz}$ antenna, applied to 4 profiles, make it possible to visualize the anomalies of the cavities and fractures of the first meters of the basement, in favor of its high spatial resolution imaging capacities and its capacity to cover quickly large shelves. The radargrams obtained characteristic of the responses of the Triassic gypsum outcrops, clearly show the existence of various cavities of different dimensions and depths which vary between $0.5 \mathrm{~m}$ to $1.5 \mathrm{~m}$. Thus, we were able to identify the appearance of several signal attenuation zones that reflect the presence of water in wetlands or dissolution zones. Profil T4 of Figure 7.

The techniques of investigation of electric tomography made it possible to unambiguously identify the resistant anomalies located less than $1 \mathrm{~m}$ deep. The underground electrical resistivity results were able to detect several underground cavities of various dimensions, sometimes exceeding tens of meters. The three $2 \mathrm{D}$ profiles measured in the gypsum formation show a high electrical resistivity of the roof of the cavities, which varies between $1328 \mathrm{Ohm} \cdot \mathrm{m}$ to $>13231 \mathrm{Ohm} \cdot \mathrm{m}$. Therefore, in each model of 3 profiles, the resistivity values at the passage of the cavities depend on the resistivity of the surrounding rocks. Some parts of the profiles show zones of low electrical resistivity interpreted by the presence of water in the dissolution zones or the wet zones.

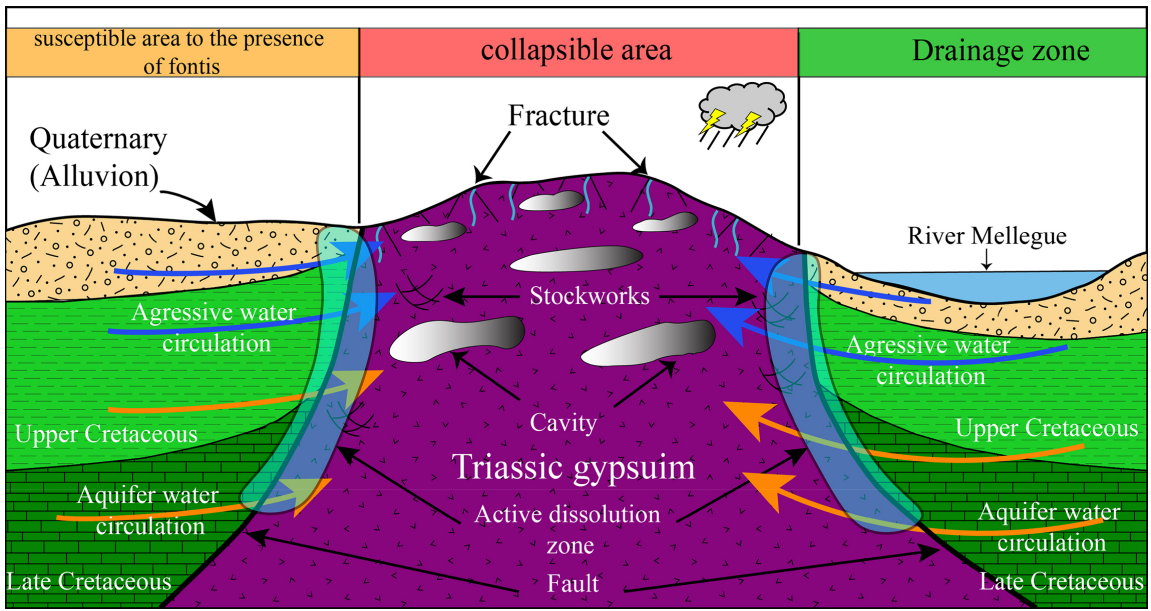

Figure 11. Schematic presentation showing the hydrogeological functioning in the Triassic outcrop of the El Fahs region and the susceptibility of soil collapse linked to the presence of underground cavities. 


\section{Conclusions and Perspective}

The susceptibility of soil collapse related to the dissolution of gypsum can be the cause of surface issues. To highlight the risks associated with the presence of stakes in the Triassic evaporites in the El Fahs region, a methodology was established to assess the predisposition and triggering factors of the hazard linked to the lithological nature of the environment.

This methodology is based on knowledge of the geological and hydrogeological contexts of the terrain studied and on the state of the soil and subsoil and to better understand the mechanisms of the establishment of the dissolution phenomenon and the appearance of cavities in the basement. To do this, a coupling between field observations and the application of geophysical methods was established.

The analysis of the predisposing factors present in the study area shows that the geodynamic context of the Triassic ascent takes place according to a precise thermodynamic process that favors the phenomenon of dissolution of the gypsum. The presence of soluble gypsum in the subsoil with a great thickness associated with the crossing of the parameters of medium (fracturing, the circulation of aggressive waters with respect to gypsum) allows obtaining a vacuum in depth associated with the dissolution. Several cavities of varying size and depth have been detected, favoring the phenomenon of soil collapse.

In favor of this approach, the geophysical methods of GPR and electrical tomography aim to detect disorders in depth. The geological radar was able to identify, following the change in the dielectric permittivity of the media, several cavities, the fractures affecting the evaporitic medium and the zones of dissolution whose investigation depth did not exceed the first 3 meters. The electric tomography method highlighted the existence of several deeper underground cavities with larger dimensions. The results between these two geophysical methods show that in the subsurface the distribution of the caves and the active dissolution zones has various depth and dimensions susceptible to the collapse of the ground.

In order to reduce the risks associated with the presence of cavities, it will be essential to put in place preventive and protective measures. It is necessary to draw up risk prevention maps linked to these phenomena in order to direct developers and decision-makers to the danger caused by the lithological nature of the land.

\section{Acknowledgements}

This research did not receive any specific grant from funding agencies in the public, commercial, or not-for-profit sectors. Thanks to Office National of Mines and the Faculty of Sciences of Bizerte to supply their $4 \times 4$ cars and driver to ensure some field missions. We gratefully acknowledge Arfaoui, A (2016) and their co-authors for their past research activities in the El Fahs area. Special thanks to the reviewers who helped to improve the quality of this manuscript. 


\section{Conflicts of Interest}

The authors declare no conflicts of interest regarding the publication of this paper.

\section{References}

[1] Ben Ayed, N. and Viguier, C. (1981) Structural Interpretation of Atlas Tunisia. CRAS Paris, 292, 1445-1448.

[2] Bou Kadi, N. (1996) New Structural Diagram for the North of Tunisia. Proceedings of the 5th Tunisian Petroleum Exploration Conference, Tunis, May 1994, Mem ETAP No. 7, 91-96.

[3] Chihi, L. (1995) The Neogenic to Quaternary Ditches of Tunisia and the Pelagian Sea: Structural Study and Their Significance in the Geodynamic Framework of the Central Mediterranean. University State Doctorate from Tunis II Faculty of Science, Tunis, $366 \mathrm{p}$.

[4] Dlala, M. (1984) Recent Tectonics and Microtectonics from the Kasserine Region (Central Tunisia). 3rd Cycle Thesis, University of Science and Technology Language, Montpellier II, $138 \mathrm{p}$.

[5] Kadri, A. (1988) Tectono-Sedimentary (Aptian-Quaternary) Evolution of the Koumine, Hamra and Lessouda Jebels (Central Tunisia). Postgraduate Thesis, Paris-Sud University, $221 \mathrm{p}$.

[6] Gutiérrez, F., Cooper, A.H. and Johnson, K.S. (2008) Identification, Prediction and Mitigation of Sinkhole Hazards in Evaporite Karst Areas. Environmental Geology, 53, 1007-1022. https://doi.org/10.1007/s00254-007-0728-4

[7] Bolze, J. (1954) Stratigraphic Position of the Salt Formations in the Far North of Tunisia. Weekly Reports of Sessions of the Academy of Sciences, 258, 4594 p.

[8] El Ouardi, H. (1996) Halokinesis and the Role of Dropouts in the Geodynamic Evolution of the Middle Part of the Domes Area (Northern Tunisia). Thesis Thesis Doctorate, Tunis, $242 \mathrm{p}$.

[9] Masrouhi, A. (2006) The Salt Systems of the Regions of Mateur, Tebourba and Medjez El Bab (Northern Tunisia). Thesis, University of Tunis El Manar, 258.

[10] Perthuisot, V. (1978) Dynamics and Petrogenesis of Triassic Extrusions in Northern Tunisia. Thesis Sciences, Univ. Pierre and Marie Curie, Paris, Presses Ecole Normale Supérieure, $312 \mathrm{p}$.

[11] Vila, J.-M. (1994) Development and New Data on the Triassic Terrain on the Algerian-Tunisian Borders: Allochthonous Triassic, Underwater "Salt Glacier" and Real Diapirs. In: Dercourt, J., Tefiani, M. and Vila, J.-M., Eds., Colloquium "Trias'93-Algeria", Memory Service of Geology, Algiers, 105-122.

[12] Zargouni, F. (1975) Geological Study of the Lansarine Range (Tébourba Region, Tunisian Atlas). 3rd Cycle Thesis, Univ. Pierre and Marie-Curie, Paris VI.

[13] Bouaziz, S., Barrier, E., Soussi, M., Turki, M.M. and Zouari, H. (2002) Tectonic Evolution of the Northern African Margin in Tunisia from Paleostress Data and Sedimentary Record. Tectonophysics, 357, 227-253. https://doi.org/10.1016/S0040-1951(02)00370-0

[14] Al-Fares, Bakalowicz, W.M., Alboury, Y., Vouillamoz, J.-M., Dukhan, M., Toe, G. and Guerin, R. (2001) Contribution of Geophysics to the Study of a Karst Aquifer-Example: The Karst Site of Lamalou. 3rd GEOFCAN Symposium, Orléans, 25-26 September 2001, 97-106. 
[15] Lagabrielle, R., Grandsert, P., Millereau, S. and Nebieridze, S. (2003) Comparative Performances of Geophysical Methods for the Detection of Cavities in Silts. Example of the SNCF Test Station on the LGV Nord, Scientific and Technical Day, Radar, Nantes.

[16] Roth, M.J.S., Mackey, J.R., Mackey, C. and Nyquist, J.E. (2002) A Case Study of the Reliability of Multielectrode Earth Resistivity Testing for Geotechnical Investigations in Karst Terrains. Engineering Geology, 65, 225-232. https://doi.org/10.1016/S0013-7952(01)00132-6

[17] Deng, S., Zuo, Z. and Wang, H. (1994) The Application of Ground Penetrating Radar to the Detection of Shallow Faults and Cavities. Proceedings of 5 th International Conference on Ground Penetrating Radar, 3, 1115-1120. https://doi.org/10.3997/2214-4609-pdb.300.83

[18] Carbonel, D., Rodríguez, V., Gutiérrez, F., McCalpin, J.P., Linares, R., Roqué, C., Zarroca, M., Guerrero, J. and Sasowsky, I. (2013) Evaluation of Trenching, Ground Penetrating Radar (GPR) and Electrical Resistivity Tomography (ERT) for Sinkhole Characterization. Earth Surface Processes and Landforms, 39, 214-227. https://doi.org/10.1002/esp.3440

[19] Pottecher, G. (1990) A Synthetic Pulse GPR Based on a Network Analyzer. Third International Conference on Ground Penetrating Radar, Denver, May 1990, 14-18

[20] Castany, G. (1955) Jurassic extrusions in Tunisia. Annales des Mines et de la Géologie Tunisien, No. 14, 71 p.

[21] Turki, M.M. (1985) Polycinematics and Associated Control on the Zaghouan Nabhana Scar. Doctoral Thesis, University of Tunis, Revue Sciences Terre, Editions Center Sciences Terre, National Institute for Technical Scientific Research Tunisia, $252 \mathrm{p}$.

[22] Arfaoui, A., Aridhi, K., Aridhi, S., Ghanmi, M. and Zargouni, F. (2016) Paleogeographic Reconstitution and Tangential Tectonic in the Backland of Tunisian Dorsal (Fahs Area: J. Rouas and Ruissate). International Journal of Geosciences, 7, 239-248. https://doi.org/10.4236/ijg.2016.73019

[23] Bajanik, S., Biely, A., Mencik, E., Salaj, J. and Stranik, Z. (1976) Geological Map of Tunisia at 1/50000 Sheets of Zaghouan-Explanatory Note. Public Service Geology, Tunis.

[24] Mjejra, M. (2015) Study of Evapotranspiration in the Mejerda Watershed (in Tunisia): Contribution of Satellite Remote Sensing and Geographic Information Systems. Geography Doctoral Thesis in Geomatics, Université Rennes 2, Rennes, 311 p.

[25] Loke, M.H. and Barker, R.D. (1996) Rapid Least-Square Inversion of Apparent Resistivity Pseudosection by a Quasi-Newton Method. Geophysical Prospecting, 44, 131-152. https://doi.org/10.1111/j.1365-2478.1996.tb00142.x

[26] Daupley, X., Laouafa, F, Billiotte, J. and Quintard, M. (2015) The Dissolution of Gypsum: Quantifying the Phenomena. Mines et Carrières, Horssérie, 35-43.

[27] Charmoille, A. and Lecomte, A. (2011) Study of Dissolution Processes Affecting the Bois de la Tussion Basement. Seine-Saint-Denis, Hazard Assessment and Proposal of Suitable Development Solutions, INERIS DRS-11-100905-02718A. 